\title{
Neighborhood Dynamics of Race and Ethnicity in the 21st Century: Residential Segregation and Poverty Concentration within Chicago, Illinois; 2000-2010
}

\author{
John Byron Strait, (PhD) \\ Samuel Adu-Prah, (PhD) \\ Sam Houston State University, United States
}

Doi: 10.19044/esj.2018.c4p3 URL:http://dx.doi.org/10.19044/esj.2018.c4p3

\begin{abstract}
Residential landscapes throughout the urban United States have long been associated with high levels of racial and ethnic segregation. The increased ethnic diversification occuring across many larger urban areas has somewhat altered this dynamic. Chicago, Illionois is one major city possessing a long history of being highly segregated residentially. The city is especially noted for the exceptionally high levels of separation that have always existed between African-Americans and whites. Like many major cities the last few years, it has increasingly became home to larger numbers of Hispanics and Asians, a trend that has altared its residential geography. This research investigates the impacts that increased diversity had on levels of residential segregation among racial and/or ethnic groups within Chicago from 2000 to 2010. Empirical analysis entailed the measurement of two dimensions of segregation evident among Non-Hispanic whites, African-Americans, Hispanics and Asians. We focus particular attention to the role that segregation has in terms of influencing degrees to which these different groups are exsposed to poverty residentially. During the decade, African-American Chicagoans as a group became slightly less residentially isolated. Conversely, results confirm that both Asians, and Hispanics appear to be exhibiting forms of "ethnic (or racial) self-selectivity" that functioned to spatially concentrate them within their own neighborhoods. The demographic composition of the city's extremly poor neighborhoods changed during the decade, yet they remained predominantly black. Findings lead us to conclude that in 2010 Chicago was still a highly segregated, albeit increasingly diverse, city.
\end{abstract}

Keywords: Urban geography, racial segregation, urban poverty, neighborhood change 


\section{Introduction}

In recent years the concept of inequality has reemerged as a major point of discussion across the U.S. As has always been the case, these discussions strongly incorporate issues of race and ethnicity. The geographic dimensions of these inequalities are one subject area given considerable attention within the scholarly community, particularly in regards to the disadvantages experienced by African-Americans residing within extremely poor urban neighborhoods (Massey and Denton 1993; Quillian 2012; Sharkey 2013). By just about any measure, socioeconomic inequalities between whites and African-Americans have worsened throughout the U.S. in recent decades. History has shown that the disparate neighborhood conditions these two racial groups experience are both the most vivid manifestation of these inequalities, and the most persistent in their severity (Massey and Denton 1993; Duneier 2016).

The disadvantages African-Americans face within urban environments stem directly from the interrelated conditions of residential segregation and poverty concentration. In short, relative to other racial and ethnic groups, African-Americans have traditionally resided within neighborhoods that are more spatially isolated and disproportionately poorer (Jargowsky 1997, 2015). For instance, it is the experiential context of racial segregation that explains how and why even many non-poor African-Americans are actually more residentially exposed to the by-products of poverty concentration than are poor whites (Massey and Denton 1993; Iceland and Hernandez 2017). It has been widely acknowledged that neighborhood experiences can actually shape everything from higher crime rates, health disparities, educational disadvantages, to limited socioeconomic mobility (Collins and Collins 2001; Strait 2006; Sampson 2012; Sharkey 2013). Thus, rather than simply being a geographic symptom of a larger system of inequality, residence within highly segregated and extremely poor neighborhoods can actually function as a root cause of a broad array of socioeconomic disadvantages that are arguably more problematic than a lack of income.

Over the last few decades urban areas in the United States have been transformed in a variety of ways, and many of these transformations that have undoubtedly altered their residential dynamics (Hardwick 2008; Ehrenhalt 2013; Frey 2010, 2012). Not all urban areas have been impacted by these transformations in the exact same manner, yet four notable nation-wide trends have impacted most large cities to some degree; (1) rapid growth in diversity and the residential dispersal of minority populations, especially Hispanics, (2) an identifiable "black flight" from cities traditionally possessing large African-American populations, (3) an influx of younger "gentrifying" whites into central cities of larger metros, and (4) the suburbanization of poverty concentration. The interaction of the changes obviously have profound 
impacts across urban landscapes, thus modifying the geographies of segregation and poverty concentration in significant ways.

The primary aim of this paper is to shed light on the evolving nature of residential segregation and poverty concentration evident among racial and ethnic groups during the first full decade of the $21^{\text {st }}$ century. We focus attention on how the aforementioned changes have manifested across the residential landscape within the core of Chicago, Illinois, a diversifying urban region that has witnessed transformations that exemplify those exhibited across the urban United States. We argue that it remains paramount to understand how city-wide diversity translates to the actual residential experiences of different racial and ethnic groups within places like Chicago, particularly in light of research suggesting that neighborhood geographies of US metropolitan areas can simultaneously be both diverse and segregated (Holloway et al. 2012; Strait and Gong 2015). In meeting its purpose this project builds upon a growing literature that has analyzed changes in residential segregation at the neighborhood level, and has considered its relationship to degrees of poverty concentration exhibited among different racial and ethnic groups (Firebaugh and Acciai 2016; Holloway et al. 2012; Iceland and Hernandez 2017; Intrator et al. 2016; Quillian 2012; Strait 2001, 2002, 2006a, 2006b; Strait and Gong 2008, 2010, 2012, 2015; Strait et al. 2007).

The following specific questions are addressed here: (1) What are the relative levels of segregation experienced among four main racial and ethnic groups in Chicago and how have they changed between 2000 and $2010 ?^{1}$ (2) How do the levels of segregation existing among these groups relate to neighborhood-level poverty exposure experienced by both the poor and the non-poor alike? (3) How has the demographic and geographic nature of extremely poor neighborhoods in Chicago changed over time? By addressing the last two questions, this paper investigates the possibilities that certain racial and/or ethnic groups may be experiencing the residential effects of urban processes in different ways, with these differences causing them to become more or less residentially exposed to poverty overtime.

\section{The Context of Chicago}

Chicago represents an important and interesting case study for an investigation such as this for a number of reasons. First, since the early part of the $20^{\text {th }}$ century Chicago has been noted for possessing a significant AfricanAmerican population, yet in recent years the city has experienced a considerable shift in its racial and ethnic make-up, largely driven by an influx of Hispanics and Asians. Second, despite a strong history as a multi-cultural city, Chicago is infamous for being among the highly segregated city in the U.S. (Sampson 2012). Moreover, the city's high levels of racial segregation 
have always intersected with very high levels of poverty concentration - poor minorities in Chicago, especially the African-American poor, have always been highly isolated from the non-poor. Third, the city has recently exhibited a degree of gentrification, whereby many neighborhoods traditionally inhabited by lower-income or modest-income minority residents have recently witnessed an influx of higher-income whites (Betancur 2010; Papachristos et al. 2011). Finally, Chicago's residential dynamics have been significantly altered by an ongoing process that totally redeveloped, and in some cases totally removed, much of its public housing stock. This process has significantly transformed many of the residential communities that traditionally served as the home for much of the African-American poor. In sum, a focus on Chicago should provide considerable insight into the impacts that urban transformations of the $21^{\text {st }}$ century are having on geographies of race, ethnicity and poverty.

\section{Data, Methodology and Conceptual Framework}

Data used in this paper were derived and tabulated from the 2000 and 2010 census tract files for the city of Chicago, Illinois. The city of Chicago serves as the demographic, cultural, and economic core of the larger ChicagoNaperville-Elgin (IL-IN-WI) metropolitan area, and in 2010 was the 3rd largest city in the United States in terms of population. The city has always contained the majority of all racial and ethnic minorities residing within the larger Chicago metro area, as well as the majority of the poor.

This study considers two different manifestations of residential segregation and required the use of two separate statistical measurements; residential evenness and residential exposure. Residential evenness, perhaps the most frequently referenced form of segregation, generally refers to the degree to which members of different groups are over-represented and/or under-represented in different sub areas relative to their overall proportions across a larger area (Massey and Denton, 1988; Massey et al., 1996). Measures of residential evenness between pairs of racial and ethnic groups were calculated via the commonly used Index of Dissimilarity (ID). ${ }^{2}$ By comparison, residential exposure is not based on some ideal or "even" distribution, but refers to the potential for different groups to experience contact through the sharing of residential space. In this paper a measure of neighborhood-level exposure was used to determine the extent to which various groups - defined by race, ethnicity, and poverty status - reside in the same neighborhoods. Unlike the index of dissimilarity, the measurement of exposure used here strongly depends on the relative sizes of the groups being considered, thus more accurately expressing the degree to which group members actually experience segregation within their neighborhood environments (Massey 1985; Massey and Denton 1988; Massey et al., 1996). 
In this study residential exposure is measured via two distinct, yet similar indices. ${ }^{3}$ One index is referred to as the isolation index and indicates the probability that an average member of a specific population would have residential contact with other members of the same population. Thus, for the purpose of this paper, increased isolation refers to the process whereby members of a particular ethnic or racial group, or just the poor members of a particular ethnic or racial group, come to increasingly reside in neighborhoods inhabited by relatively larger numbers of the same group. For example, this index could be used to calculate the proportion of the total population residing with the average Hispanics' neighborhood that is also Hispanic. Likewise, this index could be used to calculate the proportion of the total population within the average poor African-American's neighborhood that is also both poor and African-American. The related interaction index is used to measure the probability that an average member of a specific population will have residential interaction with, or exposure to, members of a different group. The interaction index can then demonstrate the proportion of the population residing within the average non-poor Hispanic's neighborhood that is either African-American, Asian and poor, or non-poor and white. Collectively these two indices essentially provide the demographic breakdown of the neighborhood inhabited by average members of the particular racial or ethnic groups being considered, as well as the poverty status of this demographic breakdown.

As a means to further investigate the evolving demographic and geographic nature of extremely poor neighborhoods, we utilized the most commonly referenced measure of extreme urban poverty; census tracts possessing overall poverty rates of $40 \%$ or more (Jargowsky 1997). The census tracts within Chicago that fit this criterion were identified for both 2000 and 2010, and demographic changes evident within them were noted.

\section{Results of Analysis}

Data in Table 1a and $1 \mathrm{~b}$ demonstrate the overall population change, and the change in the poverty population, that occurred throughout Chicago during the decade. The total population of the city declined by $7.6 \%$, and group-specific totals declined for every racial and ethnic group considered, with the exception of Asians. Chicago's poor population mirrored its overall population by becoming slightly more diverse by 2010 . Poverty increased throughout the city in both relative and absolute terms (Table 1b), as the white, Hispanic, and Asian populations all became at least slightly poorer over the decade. The increase in poverty among these groups were partially offset by relative and absolute declines in African-American poverty. Members of this racial minority still comprised over half the of the city's poverty population in 
2010, yet the total number of poor African-Americans in Chicago declined by over $7 \%$ during the decade.

Table 1a. Population Change Among Racial and Ethnic Groups in the City of Chicago; 2000 - 2010

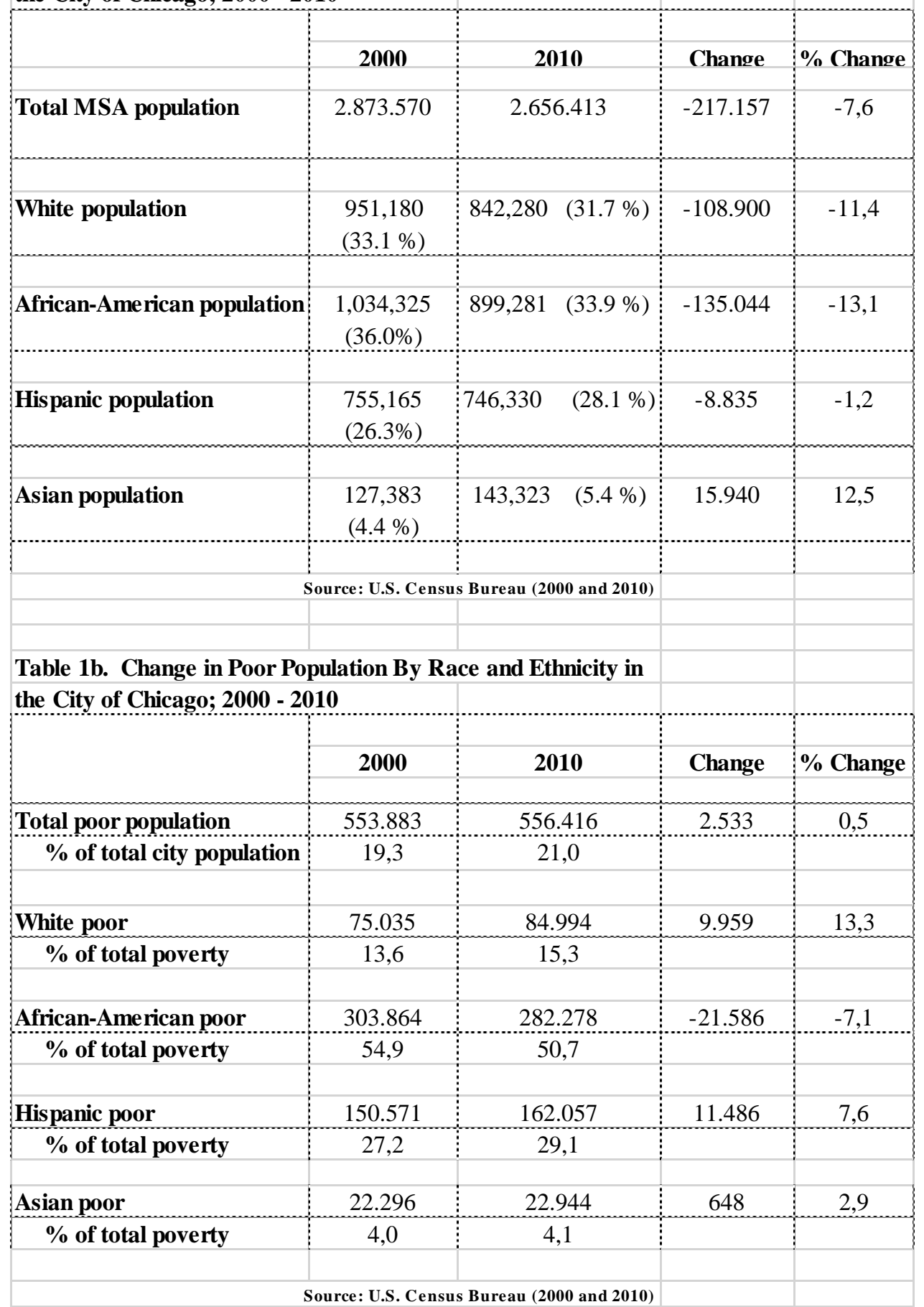


Figures 1 through 4 cartographically demonstrate the relative distributions of the groups considered here, defined by race, ethnicity, and poverty status. Figures $1 \mathrm{a}$ and $1 \mathrm{~b}$ clearly show that the northern portions of the Chicago are predominantly inhabited by the city's white population, both poor and non-poor. Comparitively, Figures $2 \mathrm{a}$ and $2 \mathrm{~b}$ demonstrate the widely acknowledged high concentrations of African Americans within the city's South and West sides. Views of Figures $1 b$ and $2 b$ cartographically reinforces the data presented in Table 1b; the concentrations of poor whites has increased across northern Chicago (Figure 1b), while the concentrations of the AfricanAmerican poor appear less prominent in 2010 (Figure 2b). Figures 3 and 4, respectively, show the increased presence of Hispanics and Asians over time. They also demonstrate that each of these groups increasingly carved out their own residential concentrations during the decade. The distribution of Asians more closely overlaps with the distribution of the white population (Figure 4a and $4 \mathrm{~b}$ ), while some Hispanic concentrations that evolved by 2010 were located near, or within, neighborhoods formerly predominated by African Americans (Figures 3a and 3b).

\section{Changes in Residential Evenness}

Table 2 includes a segregation matrix showing measures of evenness evident among the four groups as measured by the index of dissimilarity for 2000 and 2010. The data indicate that the segregation continuum evident between whites and the various minority groups in Chicago generally mirrors the trend typically evident across the rest of the metropolitan U.S. (Logan and Stults 2010; Glaesar and Vigdor 2012; Strait and Gong 2015). AfricanAmericans were more segregated from whites than other minority groups and were also the most the residentially segregated group overall. The degree of separation between African-Americans and all other groups, while still exceptionally high, did decline slightly over time. Still, the pair-wise indices are interpreted to suggest that over $83 \%$ of African-Americans would have to be relocated across Chicago in order for perfect spatial integration with any other group to be realized. As is typical elsewhere, Asians in Chicago were more integrated with whites than other groups, while Hispanics exhibited intermediate, yet fairly high, levels of segregation with the white majority. In fact, the Hispanic population exhibited fairly high levels with all groups, and demonstrated no sign of integrating with Whites or Asians during the time frame. 
Table 2. Measures of Residential Evenness Among

Racial and Ethnic Groups in Chicago, Illinois; 2000 and 2010 (2000 figures in parenthesis; based on the Index of Dissimilarity)

\begin{tabular}{|c|c|c|c|c|}
\hline & Whites & $\begin{array}{l}\text { African- } \\
\text { Americans }\end{array}$ & Hispanics & Asians \\
\hline Whites & X & $\begin{array}{c}83.0 \\
(86.0)\end{array}$ & $\begin{array}{c}60.1 \\
(60.1)\end{array}$ & $\begin{array}{c}45.0 \\
(48.8)\end{array}$ \\
\hline $\begin{array}{c}\text { African- } \\
\text { Americans }\end{array}$ & $\begin{array}{c}83.0 \\
(86.0)\end{array}$ & X & $\begin{array}{c}83.1 \\
(86.0)\end{array}$ & $\begin{array}{c}85.2 \\
(86.0)\end{array}$ \\
\hline Hispanics & $\begin{array}{c}60.1 \\
(60.1)\end{array}$ & $\begin{array}{c}83.1 \\
(84.7)\end{array}$ & X & $\begin{array}{c}67.1 \\
(67.0)\end{array}$ \\
\hline Asians & $\begin{array}{c}45.0 \\
(48.8)\end{array}$ & $\begin{array}{r}85.2 \\
(86.0)\end{array}$ & $\begin{array}{c}67.1 \\
(67.0)\end{array}$ & $X$ \\
\hline
\end{tabular}

Source: U.S. Census Bureau (2000 and 2010)

\section{Changes in Residential Exposure}

Tablea $3 \mathrm{a}$ and $3 \mathrm{~b}$ list measures of residential exposure exhibited by the four groups as measured by both isolation and exposure indices, defined by race, ethnicity, and poverty status. These indices are influenced by changes in the relative group compositions, so they would be expected to change over time. To some degree, these changes reflect the increased diversity evident across the city, along with a slight increase in exposure among the different groups. African-Americans and whites became more exposed to Hispanics and Asians over the decade, and slightly more exposed to one another (Table $3 a$ ). Findings demonstrate that on average, Asians and Hispanics resided in neighborhoods that were far more diverse than those inhabited by AfricanAmericans or whites. For example, in 2010 the average Asian resident in Chicago resided in a neighborhood that was $45.8 \%$ white, $10.8 \%$ AfricanAmerican, 21.6\% Hispanic and 21.4\% Asian (Table 3b). It is worth noting, however, that the proportion of non-Asians residing in the average Asian's neighborhood did decline for all groups overtime. In short, Asians are similar to other groups in Chicago in that they generally reside in neighborhoods inhabited by a disproportionately high number of people sharing the same racial identity. These results confirm that African-Americans in Chicago still reside in neighborhoods that are predominantly black ( $82 \%$ black), although on average these neighborhoods had become slightly less black by 2010 (Table 3a). By comparison, Hispanics were not as spatially concentrated as African- 
Americans, but in 2010 did reside in neigborhoods where over $60 \%$ of the residents were co-ethnics (Table $3 b$ ).

Table 3a. Neighborhood Exposure Indices by Race,

Ethnicity, and Poverty Status in Chicago; 2000 - 2010

\begin{tabular}{|c|c|c|c|c|}
\hline & 2000 & 2010 & Change & $\%$ Change \\
\hline \multicolumn{5}{|l|}{ Whites to: } \\
\hline Whites & 0.649 & 0.613 & -0.036 & -5.5 \\
\hline Poor Whites & 0.043 & 0.055 & 0.012 & 27.9 \\
\hline Non-Poor Whtes & 0.606 & 0.558 & -0.048 & -7.9 \\
\hline African-Americans & 0.076 & 0.086 & 0.010 & 13.2 \\
\hline Poor African-Americans & 0.017 & 0.024 & 0.007 & 41.2 \\
\hline Non-Poor African-Americans & 0.059 & 0.062 & 0.003 & 5.1 \\
\hline Hispanics & 0.211 & 0.241 & 0.030 & 14.2 \\
\hline Poor Hispanics & 0.033 & 0.041 & 0.008 & 24.2 \\
\hline Non-Poor Hispanics & 0.178 & 0.180 & 0.002 & 1.1 \\
\hline Asians & 0.062 & 0.078 & 0.016 & 25.8 \\
\hline Poor Asians & 0.009 & 0.011 & 0.002 & 22.2 \\
\hline Non-Poor Asians & 0.053 & 0.067 & 0.014 & 26.4 \\
\hline Total Poverty & 0.102 & 0.131 & 0.029 & 28.4 \\
\hline \multicolumn{5}{|l|}{ African Americans to: } \\
\hline Whites & 0.070 & 0.081 & 0.011 & 15.7 \\
\hline Poor Whites & 0.009 & 0.011 & 0.002 & 22.2 \\
\hline Non-Poor Whtes & 0.061 & 0.070 & 0.009 & 14.8 \\
\hline African-Americans & 0.846 & 0.820 & -0.026 & -3.1 \\
\hline Poor African-Americans & 0.253 & 0.258 & 0.005 & 2.0 \\
\hline Non-Poor African-Americans & 0.593 & 0.562 & -0.031 & -5.2 \\
\hline Hispanics & 0.068 & 0.080 & 0.012 & 17.6 \\
\hline Poor Hispanics & 0.017 & 0.019 & 0.002 & 11.8 \\
\hline Non-Poor Hispanics & 0.051 & 0.061 & 0.010 & 19.6 \\
\hline Asians & 0.014 & 0.017 & 0.003 & 21.4 \\
\hline Poor Asians & 0.003 & 0.003 & 0.000 & 0.0 \\
\hline Non-Poor Asians & 0.011 & 0.014 & 0.003 & 27.3 \\
\hline Total Poverty & 0.282 & 0.291 & 0.009 & 3.2 \\
\hline
\end{tabular}

Source: U.S. Census Bureau (2000 and 2010) 
Table 3b. Neighborhood Exposure Indices by Race,

Ethnicity, and Poverty Status in Chicago; 2000 - 2010

\begin{tabular}{|c|c|c|c|c|}
\hline & 2000 & 2010 & Change & $\%$ Change \\
\hline \multicolumn{5}{|l|}{ Hispanics to: } \\
\hline Whites & 0.266 & 0.220 & -0.046 & -17.3 \\
\hline Poor Whites & 0.026 & 0.029 & 0.003 & 11.5 \\
\hline Non-Poor Whtes & 0.240 & 0.191 & -0.049 & -20.4 \\
\hline African-Americans & 0.093 & 0.130 & 0.037 & 39.8 \\
\hline Poor African-Americans & 0.029 & 0.097 & 0.068 & 234.5 \\
\hline Non-Poor African-Americans & 0.064 & 0.033 & -0.031 & -48.4 \\
\hline Hispanics & 0.598 & 0.609 & 0.011 & 1.8 \\
\hline Poor Hispanics & 0.128 & 0.138 & 0.010 & 7.8 \\
\hline Non-Poor Hispanics & 0.470 & 0.471 & 0.001 & 0.2 \\
\hline Asians & 0.038 & 0.042 & 0.004 & 10.5 \\
\hline 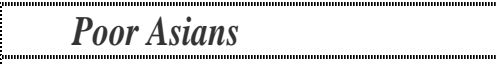 & 0.006 & 0.006 & 0.000 & 0.0 \\
\hline Non-Poor Asians & 0.032 & 0.036 & 0.004 & 12.5 \\
\hline Total Poverty & 0.189 & 0.270 & 0.081 & 42.9 \\
\hline \multicolumn{5}{|l|}{ Asians to: } \\
\hline Whites & 0.465 & 0.458 & -0.007 & -1.5 \\
\hline Poor Whites & 0.046 & 0.051 & 0.005 & 10.9 \\
\hline Non-Poor Whtes & 0.419 & 0.407 & -0.012 & -2.9 \\
\hline African-Americans & 0.114 & 0.108 & -0.006 & -5.3 \\
\hline Poor African-Americans & 0.029 & 0.032 & 0.003 & 10.3 \\
\hline Non-Poor African-Americans & 0.085 & 0.076 & -0.009 & -10.6 \\
\hline Hispanics & 0.224 & 0.216 & -0.008 & -3.6 \\
\hline Poor Hispanics & 0.038 & 0.045 & 0.007 & 18.4 \\
\hline Non-Poor Hispanics & 0.186 & 0.171 & -0.015 & -8.1 \\
\hline Asians & 0.192 & 0.214 & 0.022 & 11.5 \\
\hline Poor Asians & 0.042 & 0.043 & 0.001 & 2.4 \\
\hline Non-Poor Asians & 0.152 & 0.171 & 0.019 & 12.5 \\
\hline Total Poverty & 0.155 & 0.171 & 0.016 & 10.3 \\
\hline
\end{tabular}

Source: U.S. Census Bureau (2000 and 2010) 
As would be expected given the compositional changes that occurred, all groups became slightly more residentially exposed to poverty over the decade. African-Americans were still more exposed to poverty in 2010 than all other groups, and on average resided in neighborhoods that were more than twice as poor as those inhabited by whites (29.1\% poor for African-Americans versus $13.1 \%$ poor for whites; Table $3 a$ ). The most signficant change evident in terms of poverty exposure pertained to the residential experiences of Hispanics. The poverty rate of the average neighborhood inhabited by Hispanics increased signficantly over time, from $18.9 \%$ to $27.0 \%$ (Table $3 \mathrm{~b}$ ). These data demonstrate that the increased poverty exposure experienced by Chicagoans was at least partially due to an increased exposure to poor members of their same respective racial and/or ethnic group. However, it is notable that all groups were increasingly exposed to poor African-Americans over time, despite the fact that the relative and absolute size of this poor cohort had declined signficantly.

\section{Nature of Extremely Poor Neighborhoods}

Table 4a provides a view of changes in the composition of extremely poor neighborhoods for both 2000 and 2010, defined by race, ethnicity and poverty status. Table $4 \mathrm{~b}$ demonstrates changes in the relative presence of the various groups within these neighborhoods. There were fewer actual neighborhoods within Chicago classified as extremely poor in 2010 than was the case at the beginning of the decade (103 versus 119 , respectfully). However, these data reveal that the overall population residing within such neighborhoods increased over time. Most of this change was almost totally due to the increased presence of the non-poor, who comprised over $52 \%$ of the population within extremely poor neighborhoods by 2010 (Table 4a). For all four racial and ethnic groups considered here, the increased presence within extremely poor neighborhoods was more significantly driven by the non-poor, rather than the poor. 
Table 4a. Composition of Extremely Poor Neighborhoods by Race and Ethnicity the City of Chicago; $2000-2010$

\begin{tabular}{|c|c|c|c|c|}
\hline Total population & $\begin{array}{c}\underline{\mathbf{2 0 0 0}} \\
225,766\end{array}$ & $\begin{array}{c}\underline{\mathbf{2 0 1 0}} \\
241,950\end{array}$ & $\begin{array}{c}\text { Change } \\
16,184\end{array}$ & $\begin{array}{c}\text { \% Change } \\
7.2\end{array}$ \\
\hline Total Poor & $\begin{array}{c}114,829 \\
(50.9)\end{array}$ & $\begin{array}{l}115,928 \\
(47.9 \%)\end{array}$ & 1,099 & 1.0 \\
\hline Total Non-Poor & $\begin{array}{l}110,937 \\
(49.1 \%)\end{array}$ & $\begin{array}{l}126,022 \\
(52.1 \%)\end{array}$ & 15,085 & 13.6 \\
\hline White population & $\begin{array}{c}7,438 \\
(3.3 \%)\end{array}$ & $\begin{array}{l}11,833 \\
(4.9 \%)\end{array}$ & 4,395 & 59.1 \\
\hline White Poor & $\begin{array}{c}2,267 \\
(1.0 \%)\end{array}$ & $\begin{array}{c}3,675 \\
(1.5 \%)\end{array}$ & 1,408 & 62.1 \\
\hline White Non-Poor & $\begin{array}{c}5,171 \\
(2.3 \%)\end{array}$ & $\begin{array}{c}8,158 \\
(3.4 \%)\end{array}$ & 2,987 & 57.8 \\
\hline $\begin{array}{l}\text { African-American } \\
\text { population }\end{array}$ & $\begin{array}{l}183,816 \\
(81.2 \%)\end{array}$ & $\begin{array}{l}189,603 \\
(78.2 \%)\end{array}$ & 5,787 & 3.1 \\
\hline Afr.-Am. Poor & $\begin{array}{l}98,776 \\
(43.7 \%)\end{array}$ & $\begin{array}{l}96,321 \\
(39.7 \%)\end{array}$ & $-2,455$ & -2.5 \\
\hline Afr.-Am. Non-Poor & $\begin{array}{c}85,040 \\
(37.6 \%)\end{array}$ & $\begin{array}{c}93,282 \\
(38.5 \%)\end{array}$ & 8,242 & 9.7 \\
\hline Hispanic population & $\begin{array}{c}30,190 \\
(13.3 \%)\end{array}$ & $\begin{array}{c}36,492 \\
(15.1 \%)\end{array}$ & 6,302 & 20.9 \\
\hline Hispanic Poor & $\begin{array}{l}11,646 \\
(5.2 \%)\end{array}$ & $\begin{array}{l}14,529 \\
(6.0 \%)\end{array}$ & 2,883 & 24.8 \\
\hline Hispanic Non-Poor & $\begin{array}{l}18,544 \\
(8.2 \%)\end{array}$ & $\begin{array}{l}21,963 \\
(9.1 \%)\end{array}$ & 3,419 & 18.4 \\
\hline Asian population & $\begin{array}{c}4,322 \\
(1.9 \%)\end{array}$ & $\begin{array}{c}4,022 \\
(1.7 \%)\end{array}$ & -300 & -6.9 \\
\hline Asian Poor & $\begin{array}{c}2,140 \\
(0.9 \%)\end{array}$ & $\begin{array}{l}1,403 \\
(0.6 \%)\end{array}$ & -737 & -34.4 \\
\hline Asian Non-Poor & $\begin{array}{c}2,182 \\
(1.0 \%)\end{array}$ & $\begin{array}{r}2,619 \\
(1.1 \%)\end{array}$ & 437 & 20.0 \\
\hline
\end{tabular}


Table 4b. Percent Population within Extremely Poor Neighborhood: by Race and Ethnicity in the City of Chicago; 2000 - 2010

\begin{tabular}{|l|c|c|c|}
\hline Total population & $\underline{\mathbf{2 0 0 0}}$ & $\underline{\mathbf{2 0 1 0}}$ & \\
\hline Total Poor & 7.86 & 9.10 & \\
Total Non-Poor & 20.73 & 20.83 & \\
White population & 4.78 & 6.00 & \\
\hline White Poor & 0.78 & 1.40 & \\
White Non-Poor & 3.02 & 4.32 & \\
& 0.59 & 1.08 & \\
African-American & 17.77 & 21.10 & \\
population & 32.51 & 34.10 & \\
Afr.-Am. Poor & 11.64 & 15.12 & \\
Afr.-Am. Non-Poor & 4.00 & 4.89 & \\
Hispanic population & 7.73 & 8.97 & \\
Hispanic Poor & 3.07 & 3.76 & \\
Hispanic Non-Poor & 3.39 & 2.81 & \\
Asian population & 9.60 & 6.11 & \\
Asian Poor & 2.08 & 2.18 & \\
Asian Non-Poor & &
\end{tabular}

Throughout the 20th century African-Americans have also comprised the majority of residents within Chicago's extremely poor neighboods. Such neighborhoods did become slightly less African-American through the first decade of the 21 st century, yet this racial group still comprised over $78 \%$ of the population within them in 2010 (Table 4a). The second largest share of residents were Hispanics, who share of the population had increased to $15 \%$ by the end of the decade. The most striking component of change evident pertains to the changing poverty-status of the African-American presence. In 2010 the largest cohort residing within extremely poor neighborhoods was still the African-American poor, yet their numbers decreased in both relative and absolute terms (Table 4a). By comparison, the presence of non-poor AfricanAmerican within these neighborhoods increased signficantly. In fact, over half of the population increase evident within these neighborhoods during the 
decade was accounted for by non-poor members of this racial minority. By 2010 the average African-American resident of an extremely poor neighborhood in Chicago was almost as likely to be living above the poverty level, rather than being poor themselves.

\section{Discussions and Conclusion}

This research confirms that city-wide demographic changes did effect the residential landscape of Chicago during the first full decade of the 20th century, albeit in certain respects these effects were quite modest. It is impossible to use the data analyzed here to distinguish population change driven by migration from that due to natural increase. Nor can these data be utilized to differentiate between in-migration from international and domestic source regions. Finally, these data cannot be used to track the relocation behavior of specific populations over time. They simply provide geographic snapshots of the relative distributions of different groups at the begining and ending of a decade. That said, results presented here clearly demonstrate the residential outcomes of, and linkages between, geographic processes operating at two scales; the impacts of city-wide diversity on levels of residential segregation, and the effects that both increased diversity and residential segregation had on neighborhood-level poverty exposure..

The implications of these results can be summarized by three main points. First, the increased diversity exhibited across the city of Chicago yielded only a very slight degree of residential integration at the neighborhood level. The integration evident at the neighborhood-scale exhibited was primarily due to the combined effects of two forces operating at the city-wide scale; the signficant outmigration of African-Americans and whites that occurred during the decade, and the relative growth exhibited among Hispanics and Asians. In this regard, increased diversity did indeed lead to minor increases in integration across the city. Yet pair-wise indices of eveneness indicate that African-Americans were the minorities that became increasingly integrated with all groups considered, changes that were very modest at best. Moreover, by the end of the decade Chicago's AfricanAmerican population still remainted one of the more geographically isolated urban cohorts in the entire United States. Comparitively, both Hispanics and Asians appear to be exhibiting certain degrees of ethnic (or racial) "selfselectivity" by increasingly residing in neighborhoods inhabited by co-ethnics (Gordon, 1964; Strait 2002).

Second, the evolving levels of residential segregation in Chicago had complex and sometimes contradictory links with the levels of poverty exposure exhibited by different racial and/or ethnic groups. For instance, there is no doubt that the tendency for African-American Chicagoans to reside in highly segregated neighborhoods results in members of this racial group being 
disproportionately exposed to poverty residentially. Evidence provided here clearly demonstrates that both the absolute and relative numbers of non-poor African-Americans residing within extremely poor Chicago neighborhoods increased during the decade, even as poor members of this racial minority became slightly less present within them. Yet, this same evidence also suggests that the modest levels of integration that did occur across the city was at least partially generated by other racial and ethnic groups becoming increasingly exposed to poor African-Americans. Integration was essentially occuring across lines of poverty status. This was particularly true for the Hispanic population, whose increased exposure to African-Americans over time was almost totally driven by an increased exposure to a poor cohort. In sum, untangling the complex impacts of racial and/or ethnic segregation on poverty exposure requires one to fully consider the race-and-class contexts of neighborhood dynamics.

Third, empirical results provide ample evidence that the evolving residential geography within Chicago was associated with alterations in the nature of the city's extremely poor neighborhoods. Given that the city's poor population had increased in relative terms during the decade, it might seem natural that a larger percentage of its population would reside in such neighorhoods. However, extremely poor neighborhoods in Chicago, at least as collectively measured here, became noticably less poor during the decade. It is counter-intuitive, but the increased population residing within extremely poor neighborhoods was driven almost exclusively by a growth in non-poor populations. Fewer poor African-Americans resided in these neighborhoods by 2010, yet this change that was more than offset by the increased presence of a non-poor racial cohort. In Chicago, extremely poor neighborhoods had became slightly less poor, and slightly more Hispanic, but in 2010 they were still predominantly black

So what do these findings tell us about the general impacts of increased diversity on levels of segregation evident across urban residential space? Or what do they tell us about residential segregation and its particular relationships to poverty concentration within Chicago? In Chicago, Illinois, as is the case across the larger urban world, the old realities of race, ethnicity and place are changing. Chicago has been in the process of exhibiting a total reconfiguration of residential space the last few decades, changes that obviously impact how different populalations share residential space. The residential changes identified here are at least partially a response to the widespread transformation of Chicago's public housing sector, a housing sector that has contributed to what has been referred to as the city's ,architecture of segregation." (Jargowsky 2015). For example, the overall decrease in Chicago's poor black population, as well as the increased exposure to this population on the part of all other groups considered, stem in part from the 
removal of the city's larger public housing projects (Austen 2018). As the housing options formerly available in certain neighborhoods changed, many poor African-Americans responded by relocating. These relocations that in some cases entailed leaving Chicago, or even leaving the state of Illinois (Diamond 2017; Moore 2017). Addressing the precise nature of these processes lie outside the primary purpose of this paper. Likewise, this research did not address a determination of what would lead members of an ethnic or racial group to choose to live in certain neighborhoods. These findings would generally support the idea that ethnic enclaves represent a natural response within an urban area experiencing rapid immigration (Gordon 1964; Iceland 2004). It is likely that the immigrant populations newly arriving to Chicago, for a variety of reasons, actively search out residential environments from which they can more easily assimilate into the broader urban fabric

The most vivd conclusion derived from this research is that, despite the effects of a number of geographic and demographic processes, in 2010 Chicago remained a highly segregated city. In the context of continued diversity, Chicago continues to live up to its reputation as a city of neighborhoods, with this geographical distinctiveness stemming at at least partially from the spatial manifestations of race and ethnicity. Results reported here reinforce Vertovec's (2007) notion that "diversity is not what it used to be." (Vertovec 2007). Chicago, being simultanously both diverse and highly segregated, could be offered as evidence that diversity and segregation are not binary opposites of one another in terms of how they manifest across urban space (Holloway et al. 2012; Strait and Gong 2015). Findings reported here provide compelling geographical evidence that race and ethnicity still matter in Chicago, even if they continue to matter in slightly different ways. 
FIGURE 1a.

\section{Percent White Poor}
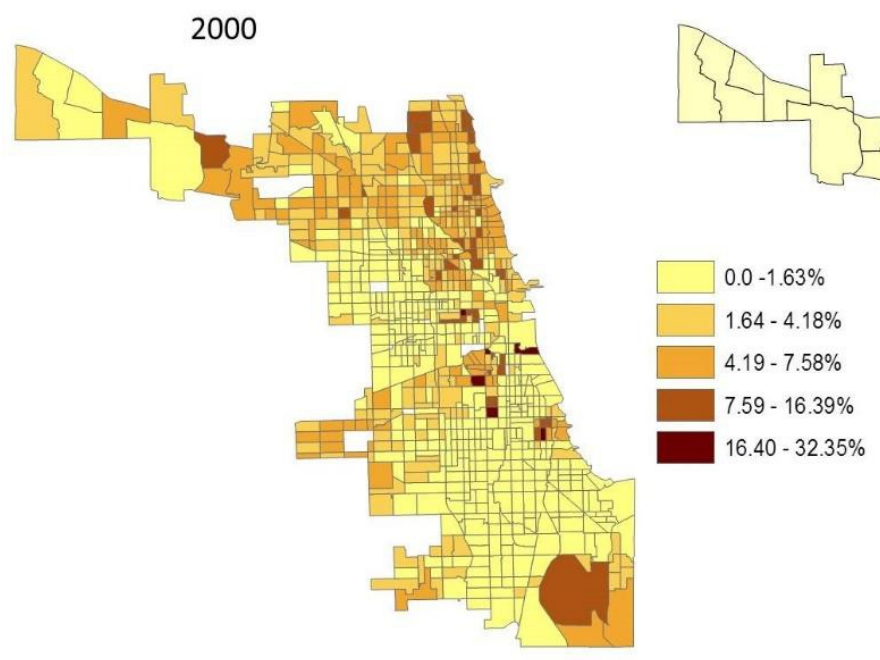

2010

FIGURE 1b.

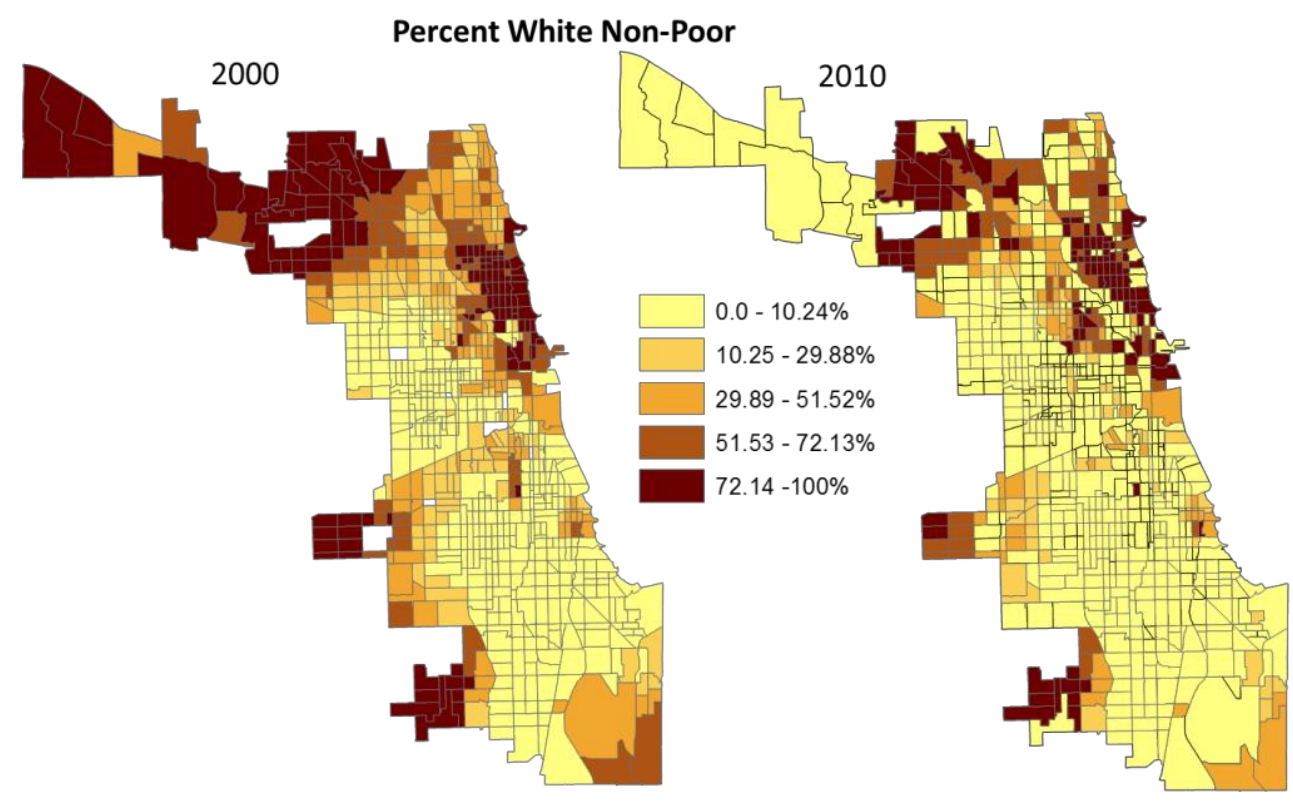




\section{FIGURE 2a.}

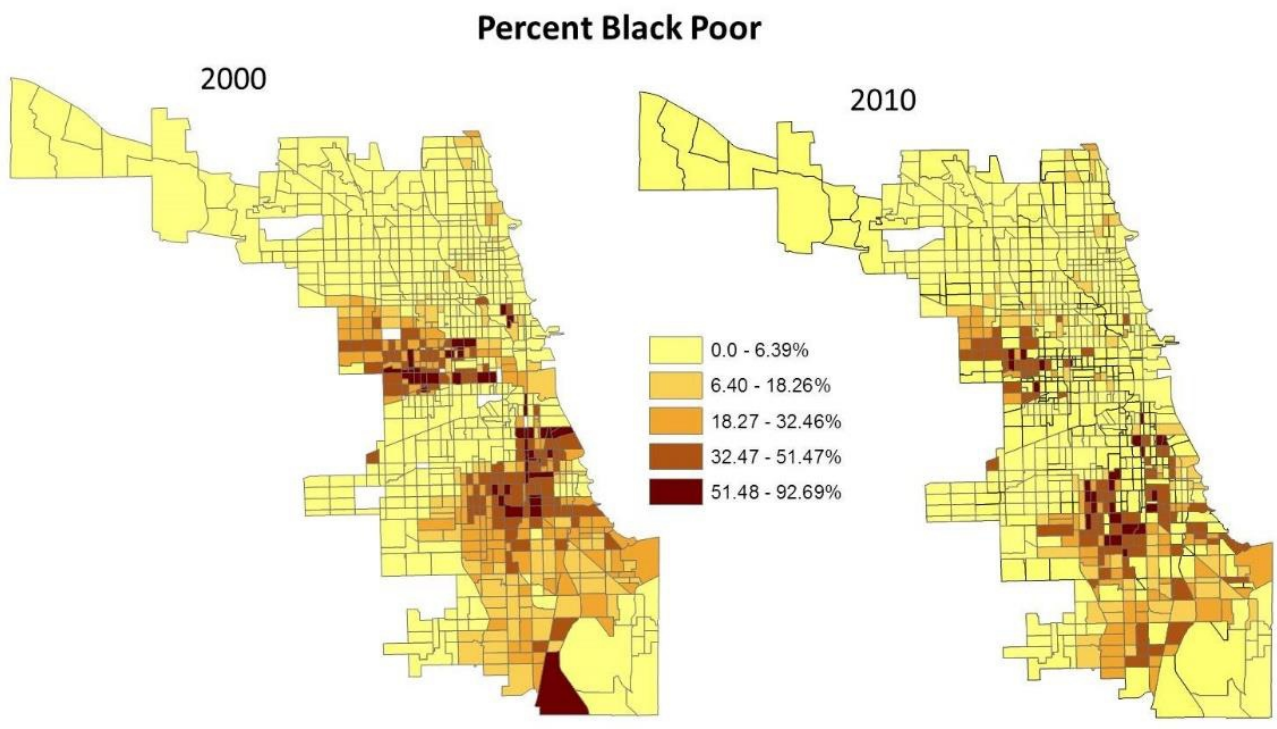

FIGURE 2b.

\section{Percent Black Non-Poor}

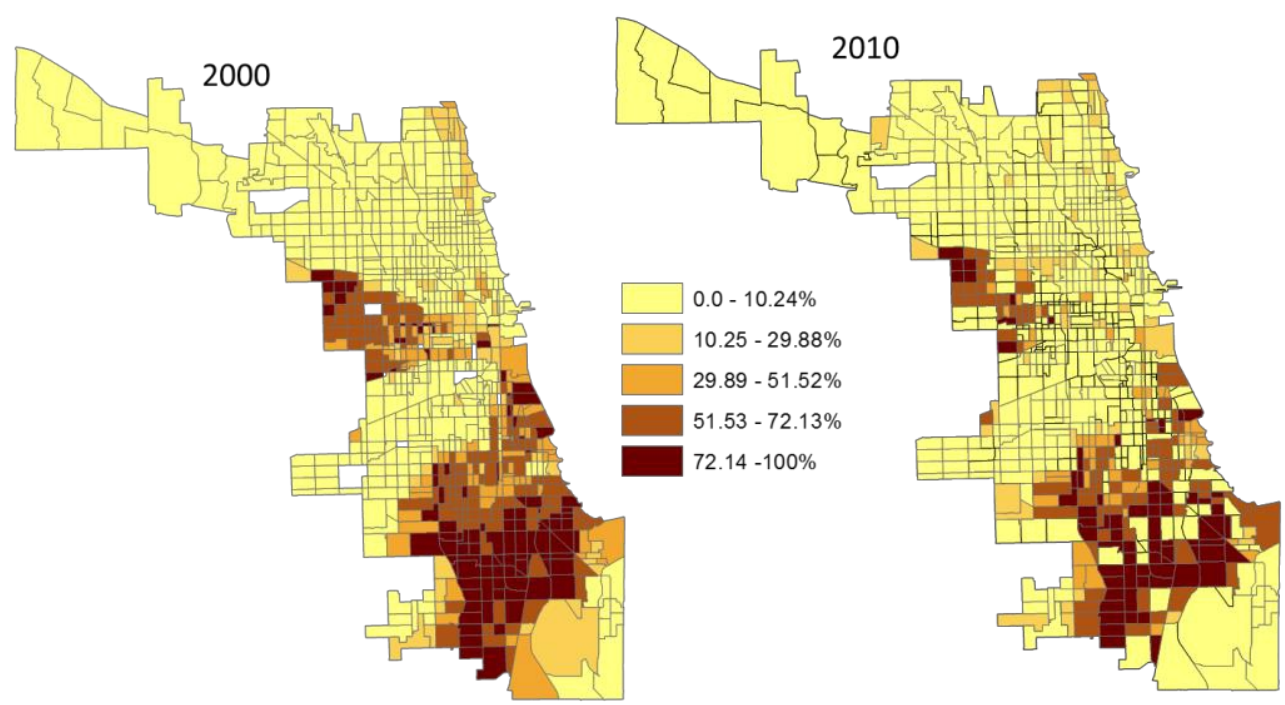


FIGURE 3a.

\section{Percent Latino Poor}

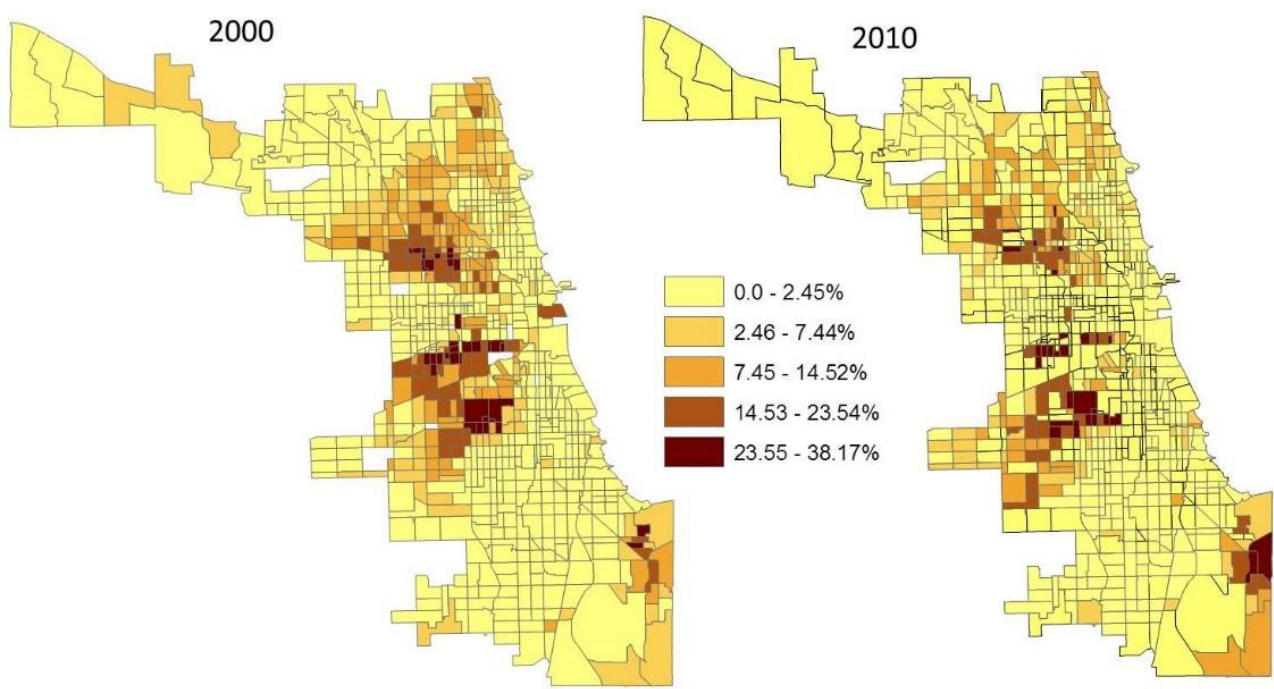

FIGURE 3b.

\section{Percent Latino Non-Poor}

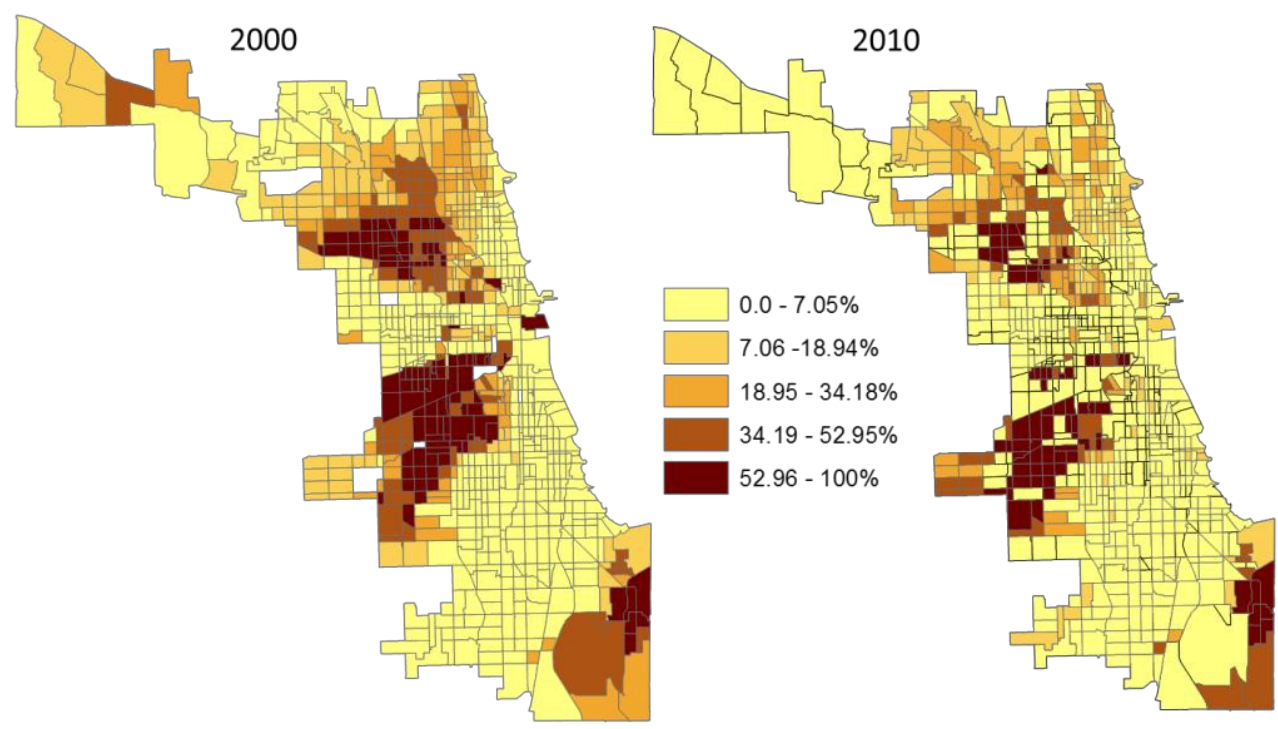


FIGURE 4a.

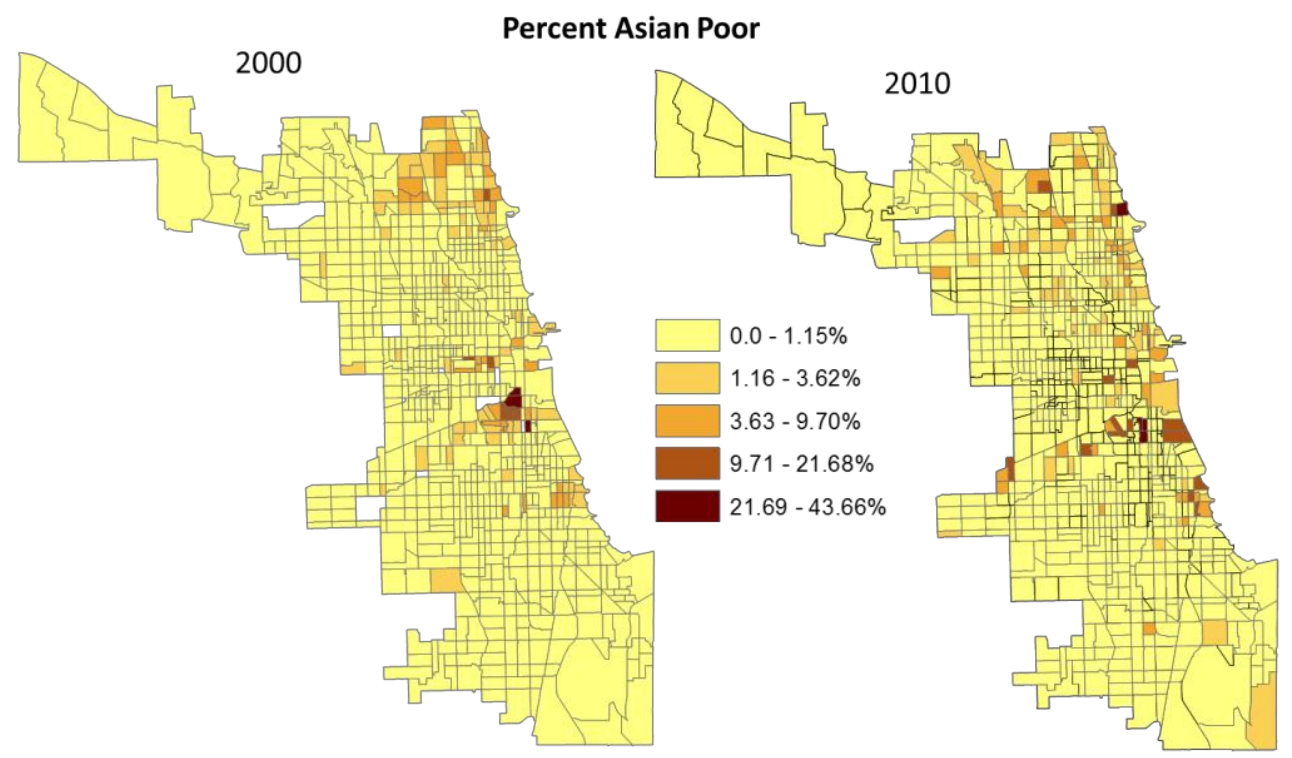

FIGURE 4b.

Percent Asian Non-Poor

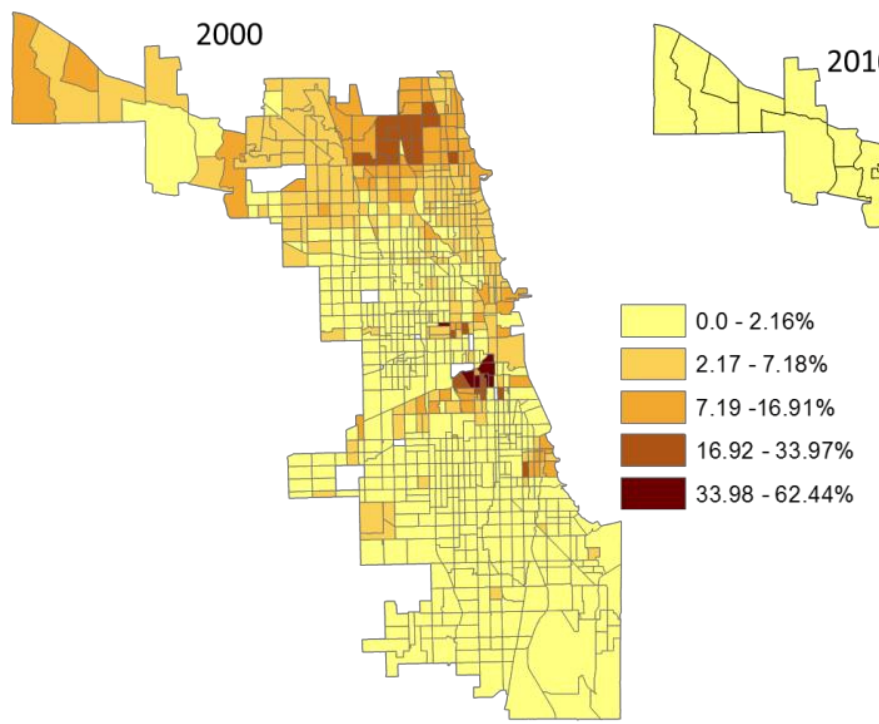

2010

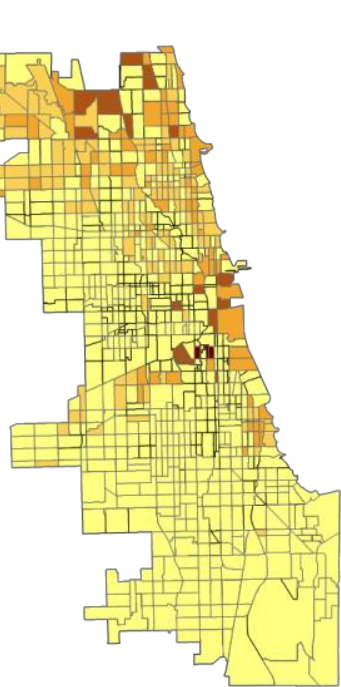

\section{Notes}

1. The terminology used in this paper to refer to different racial/ethnic groups follows the U.S. Census Bureau; Whites (a term used here to refer to Non-Hispanic whites), African-Americans, Hispanics, and Asians. In order to compare population counts among racial and ethnic groups over different 
census years, the multiracial population identified in 2000 and 2010 was excluded for the purpose of empirical analysis. The authors acknowledge that the particular categories coded by the U.S. Census may not be the most accurate way to gauge racial/ethnic identity, given that such categories represent social constructs that cannot be measured biologically (Omni and Winant 2014). For obvious reasons, however, the methodology utilized here requires the use of such census-defined categories. Moreover, geographical research, including findings reported in this paper, demonstrate that such categories do indeed have a geographical dimension. At times throughout this paper the terms black and African-American are used interchangeably.

2. The basic formula for the index of dissimilarity is:

$$
\frac{1}{2} \sum_{i=1}^{N}\left|\frac{b_{i}}{B}-\frac{w_{i}}{W}\right|
$$

where (comparing a black and white population, for example):

$b_{i}=$ the black population of the $i^{\text {th }}$ area, e.g. census tract

$B=$ the total black population of the large geographic entity for which the index is being calculated.

$w_{i}=$ the white population of the $i^{\text {th }}$ area

$W=$ the total white population of the large geographic entity for which the index is being calculated.

This index ranges from 0 to 100 and is conceptually interpreted as reflecting the percentage of either group's population that would have to change neighborhood residence in order for one group to become evenly distributed across the study area relative to another.

3. The most common formula for the isolation index is the following:

$$
x P x^{*}=\sum_{i=1}^{I}\left(\frac{x i}{X}\right) *\left(\frac{x i}{t i}\right)
$$

where $\mathrm{t}_{i}$ is the total population of tract $i, \mathrm{x}_{i}$ is the number of group-X members in tract $i$, and $X$ is the total number of group-X members in the largest metropolitan region in question. The measure is interpreted as representing group-X's proportion of the population in the residential tract of an average group-X member. The related exposure index is

$$
x P y^{*}=\sum_{i=1}^{I}\left(\frac{x i}{X}\right) *\left(\frac{y i}{t i}\right)
$$

where $t_{i}, x_{i}$, and $X$ are the same terms as before, and $y_{i}$ represents the number of group-Y members in tract $i$. This index then measures the potential that an average member of group- $\mathrm{X}$ will have residential contact with, or exposure to, members of group-Y within their neighborhood environment. 


\section{References:}

1. Austen, Ben. High Risers: Cabrini-Green and the Fate of American Public Housing. New York: Harper. 2018.

2. Betancur, John. 2010. Gentrification and community fabric in Chicago. Urban Studies 48 (2): 383-406.

3. Diamond, Andrew. Chicago on the Make: Power and Inequality in a Modern City. Berkely, CA: University of California Press. 2017.

4. Duneier, Mitchell. Ghetto: The Invention of a Place, the History of an Idea. New York: Farrar, Straus, and Giroux. 2016.

5. Ehrenhalt, Alan 2013. The Great Inversion and the Future of the American City. New York: Vintage.

6. Firebaugh, Glenn, and Francesco Acciai. 2016. For blacks in America, the gap in neighborhood poverty has declined faster than segregation. Proceedings of the National Academy of Sciences of the United States of America 113(47): 13372-13377.

7. Frey, William. 2010. The State of Metropolitan America. Brookings Institute, Metropolitan Policy Program

8. 2012. The Status of Metropolitan America, Part II, Race and Ethnicity. A report by the Brookings Institute.

9. Glaesar, Edward and Jacob Vigdor. 2012. Civic Report No. 66: The End of the Segregated Century: Racial Separation in America's Neighborhoods, 1890-2010. A report by the Manhattan Institutes Center for State and Local Leadership. New York, NY.

10. Gordon, M. M. Assimilation in American life. New York: Oxford University Press. 1964.

11. Holloway, Steve, Richard Wright, and Mark Ellis. 2012. The Racially Fragmented City? Neighborhood Racial Segregation and Diversity Jointly Considered. Professional Geographer 64 (1): 63-82.

12. Hardwick, Susan W. 2008. Toward a suburban immigrant nation. In Twenty-first Century Gateways: Immigrant Incorporation in Suburban America, ed. Audrey Singer, Susan W. Hardwick and Caroline B. Brettell, 31-50. Washington DC: Brookings Institute.

13. Iceland, J. 2004. Beyond black and white: Metropolitan residential segregation in multi-ethnic America. Social Science Research, 33, 248-71.

14. Iceland, John and Erik Hernandez. 2017. Understanding trends in concentrated poverty, 1980-2014. Social Science Research 62: 75-95.

15. Intrator, Jake, Jonathan Tunnen, and Douglas Massey. 2016. Segregation by race and income in the United States, 1970-2010. Social Science Research 60:45-60.

16. Jargowsky, Paul. Poverty and Place: Ghettos, Barrios and the American City. New York: Russel Sage Foundation. 1997. 
17.

Architecture of segregation: Civil unrest, the concentration of poverty, and public policy. New York City: The Century Foundation. 2015.

18. Lewinnek, Elaine. The Working Man's Reward: Chicago's Early Suburbs and the Roots of American Sprawl. Oxford: Oxford University Press. 2014.

19. Logan, J.R. and B. J. Stults. 2010. Racial and Ethnic Separation in the Neighborhoods: Progress at a Standstill. A research report published by the American Community Project, Russell Sage Foundation.

20. Massey, Douglas S. and Nancy A. Denton. American Apartheid: Segregation and the Making of the Underclass. Harvard: Harvard University Press. 1993.

21. Moore, Natalie. South Side: A Portrait of Chicago and American Segregation. New York: Picador Publishing. 2017.

22. Nightingale, Carl H. Segregation: A Global History of Divided Cities. Chicago: University of Chicago Press. 2012.

23. Omni, Michael and Howard Winant. Racial Formation in the United States. New York: Routledge. 2014.

24. Papachristos, Andrew V, Chris M. Smith, Mary L. Scherer, and Melissa A. Fugiero. 2011. More coffee, less crime? The relationship between gentrification and neighborhood crime rates in Chicago, 1991 to 2005. City and Community 10(3): 215-240.

25. Quillian, Lincoln. 2012. Segregation and poverty concentration: The role of three segregations. American Sociological Review 77 (3): 354379.

26. Sampson, Robert J. Great American City: Chicago and the Enduring Neighborhood Effect. Chicago: University of Chicago Press. 2012.

27. Sharkey, Patrick. Stuck in Place: Urban Neighborhoods and the End of Progress Toward Racial Equality. Chicago: University of Chicago Press. 2013.

28. Strait, J.B. 2001. The impact of compositional and redistributive forces on poverty concentration: The case of the Atlanta, Georgia metropolitan region, 1980-1990. Urban Affairs Review 37: 19-42.

29. 2002. Poverty concentration in a multi-ethnic city: The impact of compositional and redistributive forces in Miami, Florida, 1980-1990. Southeastern Geographer 42: 159-182.

30. 2006. Poverty concentration in the prismatic metropolis: The impact of compositional and redistributive forces within Los Angeles, California; 1990-2000. Journal of Urban Affairs 28: 71-94.

31. Strait, John B. 2006. The epidemiology of urban poverty: The impact of poverty concentration on infant mortality among African- 
Americans and whites, 1982-1999. Professional Geographer 58: 3953.

32. Strait, J. B. and G. Gong. 2008. Poverty evolution in the capital of the Sunbelt: An investigation of neighborhood-level poverty among racial and ethnic groups within Houston, Texas; 1990-2000. Southwestern Geographer 12: 40-70.

33. - 2010. Ethnic Diversity in Houston, Texas: The Evolution of Residential Segregation in the Bayou City, 1990-2000. Population Review 49 (1): 53-79. 2012. An Evolving Residential landscape in post-Katrina New Orleans: Residential segregation among racial and ethnic groups, 2000-2010. International Journal of Applied Geospatial Research 3(4 ):1-19.

35. Strait, John B. and Gang Gong. 2015. The impact of increased diversity on the residential landscape of a Sunbelt metropolis: Racial and ethnic segregation in the Atlanta metropolitan region; $1990-$ 2010. Southeastern Geographer 55(2): 121-144.

36. Strait, John. B., Gang Gong, and Cherisha Williams. 2007. Rubbing elbows in the Big Easy: Residential segregation among racial and ethnic groups in New Orleans, Louisiana; 1990-2000. Southeastern Geographer 47: 254-282.

37. Vertovec, Steve. 2007. Super-diversity and its implications. Ethnic and Racial Studies 30(6): 1024-54.

38. Williams, D.R. and C. Collins. 2001. Racial residential segregation: A fundamental cause of racial disparities in in health. Public Health Reports 2001 116(5): 404-416. 